\title{
Stimulating effects of chlordiazepoxide in rats on a food reinforced $F R$ schedule
}

PAUL W. WEDEKING, DEPARTMENT OF PHARMACOLOGY, THE SQUIBB INSTITUTE FOR MEDICAL RESEARCH, New Brunswick, N.J.08903

In rats conditioned on an FR 25 schedule with a 10 sec time out, various dose levels of chlordiazepoxide produced significant increases in response rates during $C S$ and in responses during time out. These increases are discussed in terms of both appetite stimulating and disinhibition effects of chlordiazepoxide.

Chlordiazepoxide (CDP) is normally considered a minor tranquilizer with behavior depressing sedation, muscle relaxation, and antianxiety ("taming") effects in both animals and man (Jarvik, 1965). However, one of the first pharmacological effects of CDP noticed by Randall, Schallek, Heise, Keith, \& Bagdon (1960) was a marked appetite stimulation in food deprived rats. Appetite stimulating effects of CDP have also been demonstrated in rats in chronic toxicity studies (Randall et al, 1960) although McDonald, Stern, \& Hahn (1963) found no effect when CDP was administered to rats on ad lib food.

Few behavioral experiments have been done to elucidate the appetite stimulating properties of CDP in rats (Cook \& Kelleher, 1963). In an assessment of psychotropic drugs on food reinforced behavior, Bainbridge (1968) observed an increase in lever presses by rats on an FR 4 schedule with sweetened milk reinforcement after an injection of $C D P$ at $8 \mathrm{mg} / \mathrm{kg}$; the increase in responding was attributed to fear reduction.

Richelle \& Djanhaguiri (1964) demonstrated that CDP given to rats on an FI 2 min food reinforced schedule increased conditioned activity (responding) and disrupted the characteristic FI temporal discrimination. Similar disruptions were observed by Richelle, Xhenseval, Fontaine, \& Thone (1962) when CDP was given to rats on a DRL schedule.

In a slightly different experiment, Gluckman (1965) studied the effects of CDP in rats trained to simultaneously run a motorized treadmill and consume condensed milk from a drinking tube; Gluckman found that rats treated with 2.5 or $5.0 \mathrm{mg} / \mathrm{kg}$ of CDP, i.p., drank more than they did without drug.

The effects of CDP have also been studied in numerous approach-avoidance, conflict, and concurrent positive and negative reinforcement experiments utilizing food as reinforcement. However, the reports of these studies do not discuss the possible influence the appetite stimulating effects of CDP may have had on the operant behavior.

This report describes the effects of CDP on a food reinforced FR schedule.

Subjects. Five randomly selected, experimentally naive, female LongEvans rats, 150 days of age at the start of experimentation, served as Ss. They were housed in individual cages with water available ad lib.

Procedure. The Ss were maintained at $80 \%$ of their pre-experimental body weight. Prior to any drug administration, each $S$ was conditioned to an asymptotic performance level on an FR 25 schedule with a white-noise tone and light $\mathrm{CS}$ in a standard rat lever-press chamber; a $15 \mathrm{~g}$ force had to be exerted on the lever by the $S$ to activate it. Reinforcement was a single $45 \mathrm{mg}$ Noyes food pellet with a $10 \mathrm{sec}$ time out period following each reinforcement. Eighty reinforcements constituted a daily session for each $S$.

The experimental chamber was housed in a ventilated sound-proof cabinet and isolated from the programming and monitoring equipment. The number of lever presses during time out and during CS were tabulated separately and the total length of time necessary to complete each daily session was recorded. A cumulative record was obtained for each session.

Various dose levels of chlordiazepoxide $\mathrm{HCl}$ were administered i.p. as aqueous solutions at $\mathrm{pH} 6$ in a dose volume of $0.1 \mathrm{ml} / 100 \mathrm{~g}$ body weight Fresh solutions of CDP were made on test days to limit decomposition effects (Ban, 1967, and Randall et al, 1960). A 7-10 day interval was allowed between drug days to reduce the possibility of drug carry over even though in the rat CDP is eliminated within 3-4 days (Randall, 1961). The five Ss were given weekly injections of the drug with each $S$ receiving each of the eight doses (in random sequence). Additional doses were given to the Ss such that each dose level was administered six times. Injections were given $15 \mathrm{~min}$ prior to placing the $S$ in the test chamber.

Results and Discussion. As shown in Fig. 1, Ss injected with CDP at dose levels of $0.5-10.0 \mathrm{mg} / \mathrm{kg}$ showed significant $(\mathrm{p}<0.01$, paired $t$-test) increases in their response rates during $C S$ and during time out when compared to their response rates on the previous day which served as control.

The previously observed appetite stimulating effects of CDP could reasonably account for the increased rate of responding during CS presentation. However, the increase in responses during time out may indicate that CDP stimulates more than just the appetite.

It is possible that the capability of CDP to break down the temporal discriminations as observed by Richelle and co-workers $(1962,1964)$ in their DRL and FI studies is also affecting the Ss in this FR experiment by disrupting their ability to discriminate the CS. However, by viewing the Ss under test and by studying their cumulative records, it was observed that the Ss appeared to operate the lever continually until they received reinforcement and that they continued to press the lever during time out but at a slower rate. The comparison between response rates during $\mathrm{CS}$ and during time out in Fig. 1 shows this difference and shows that there was apparently no breakdown in CS discrimination.

Recently, Margules \& Stein (1967) suggested that tranquilizer drugs, in general, may produce increases in the rate of previously suppressed behavior by releasing the behavior from inhibition (disinhibition). Considering the time out period as a response inhibiting stimulus (Ferster \& Skinner, 1957), the increase in responses during time out could be attributed to the disinhibition effects of CDP. In another behavioral study, Steiner, Fitzgerald, \& Taber (1967) ascribed the reduction of rate of extinction of a shuttle avoidance by rats treated with CDP to the disinhibition effects of CDP.

The results also seem to indicate that CDP may exert appetite stimulating effects as well as disinhibition effects at approxinately the same dose levels. However, in a conditioned behavioral situation, the appetite stimulating effects can be masked by the other effects (ataxia, muscle relaxation, sedation, etc.) produced by CDP at higher dose levels $(10.0-10.0 \mathrm{mg} / \mathrm{kg})$ as seen in Fig. 1 by the decreases in the response rates during CS and time out since in food consumption experiments, CDP stimulates the appetite at doses up to $50.0 \mathrm{mg} / \mathrm{kg}$, s.c. (Randall et al, 1960).

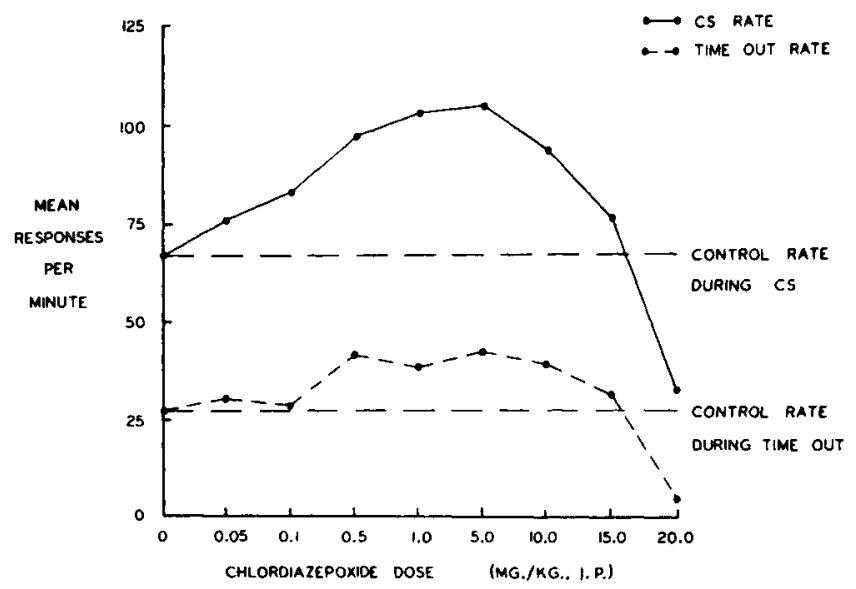

Fig. 1. Comparison of the effects of chlordiazepoxide given to rats on response rates during $\mathrm{CS}$ and during time out. 


\section{REFERENCES}

BAINBRIDGE, J. G. The effect of psychotropic drugs on food reinforced behaviour and on food consumption. Psychopharmacologia, 1968, 12, 204213.

BAN, T. A. Clinical pharmacology of psychotropic drugs. App. Therap., 1967, 9, 366-371.

COOK, L., \& KELLEHER, R. T. Effects of drugs on behavior. Ann. Rev. Pharm, 1963, 3, 205-222.

FERSTER, C., \& SKINNER, B. F. Schedules of reinforcement. New York: Appleton-Century-Crofts, 1957.

GLUCKMAN, M. I. Pharmacology of oxazepam (Serax), a new antianxiety agent. Cur. Ther. Res, 1965, 7, 721-739.

JARVIK, M. E. Drugs used in the treatment of psychiatric disorders. In L. S. Goodman and A. Gilman (Eds.), The pharmacological basis of therapeutics, (3rd ed.). New York: Macmillan, 1965. Pp. 159-214.

MARGULES, D. L., \& STEIN, L. Neuroleptics vs. tranquilizers: Evidence from animal behavior studies of mode and site of action. In H. Brill (Ed.), Neuropsychopharmacology. New York: Medica Foundation, 1967. Pp.
108-120.

McDONALD, D. G., STERN, J. A., \& HAHN, W. W. Behavioral, dietary and autonomic effects of chlordiazepoxide in the rat. Dis. Nen. Syst., 1963, 24, 95-103.

RANDALL, L. O. Pharmacology of chlordiazepoxide (Librium). Dis. Nerv. Syst., 1961, 22 (suppl.), 7-15.

RANDALL, L. O., SCHALLEK, W., HEISE, G. A., KEITH, E. F., \& BAGDON, R. E. The psychosedative properties of methaminodiazepoxide. J. Pharmacol exp. Therap., 1960, 129, 163-171.

RICHELLE, M., \& DJAHANGUIRI, B. Effet d'un traitement prolongé au chlordiazepoxide sur un conditionnement temporel chez le rat. Psychopharmacologia, 1964, 5, 106-114.

RICHELLE, M., XHENSEVAL, B., FONTAINE, O., \& THONE, L. Action of chlordiazepoxide on two types of temporal conditioning in rats. Int. J. Neuropharmacol, 1962, 1, 381-391.

STEINER, S. S., FITZGERALD, H. L., \& TABER, R. I. Effect of chlordiazepoxide (CDP) on acquisition and extinction of shuttle box and pole-climb avoidance. The Pharmacologist, 1967, 9, 200. 